\title{
Clinical Trial Safety Documentation
}

National Cancer Institute

\section{Source}

National Cancer Institute. Clinical Trial Safety Documentation. NCI Thesaurus. Code

C115630.

Records detailing the policies and procedures of the safety measures within a clinical trial. 